\title{
A regulação jurídica constitucional dos meios e a monopolização das transmissões esportivas
}

\author{
The legal constitutional regulation of media and the monopolization of sport \\ broadcasting
}

\author{
Bárbara Bressan Belan1 \\ (ba_92_b@hotmail.com) \\ Carlo José Napolitano2 \\ (carlonapolitano@faac.unesp.br) \\ http://dx.doi.org/10.5216/cei.v14i1.21503
}

\begin{abstract}
Resumo
Trata-se o presente de apresentação de resultados de pesquisa de iniciação científica, que teve por escopo analisar a regulação jurídica constitucional produzida durante o processo constituinte de 87/88 acerca do direito de propriedade dos meios de comunicação social, no intuito de investigar a proibição constitucional de monopólio e de oligopólio na apropriação dos meios. A proposta de pesquisa considera que essa proibição representa também, como consequência, a vedação da monopolização e da oligopolização na veiculação de informações, pressupondo um mercado plural e diversificado. Considera ainda que, não obstante a proibição legal, no plano da realidade concreta algumas empresas de comunicação monopolizam determinados setores da economia, controlando o fluxo de informações, como pode ser verificado na recente questão acerca do monopólio dos direitos de transmissão dos jogos do Campeonato Brasileiro de Futebol da Série A, por parte da Rede Globo de Televisão, tema que será utilizado para justificar a ilegalidade apontada para o setor. Nesse sentido, a pesquisa revisitou o processo constituinte no intuito de analisar os projetos e debates legislativos que resultaram na atual regulação constitucional do direito de propriedade dos meios de comunicação social, bem como analisou a decisão proferida pelo Conselho Administrativo de Defesa Econômica (CADE) em relação ao monopólio da Rede Globo nas transmissões do Brasileirão, série A.
\end{abstract}

Palavras-chave: Comunicação social. Exclusividade. Monopólio. Oligopólio. Regulação dos meios.

\begin{abstract}
This is a presentation of results referring to a undergraduate research which analyze the legal constitutional regulation produced during the constituent process of $87 / 88$ about the ownership of the media, in order to investigate the constitutional ban monopoly and oligopoly in media ownership. The research considers that this prohibition represents, as a consequence, a seal against monopolization and oligopoly in the transmission of information, assuming a plural and diverse market. Further considers that, notwithstanding the statutory prohibition, on the plane of reality some media companies monopolize certain sectors of the economy, controlling the flow of information, as can be seen in the recent issue about the monopoly of the broadcasting rights for the Premier League games Football Series by the Globo Television Network, a theme that will be used to justify the illegality pointed to the sector. In this sense, the research revisited the constitutional process in order to analyze the projects and legislative debates that led to the current constitutional regulation of ownership of the media, as well as analyzed the decision of the Administrative Council for Economic Defense (CADE) in relation to monopoly Globo broadcasts in the Brasileirão, Series A.
\end{abstract}

\footnotetext{
${ }^{1}$ Discente do curso de Jornalismo da Faculdade de Arquitetura Artes e Comunicação da UNESP/Bauru, bolsista de iniciação científica da Fundação de Amparo à Pesquisa do Estado de São Paulo (FAPESP).

${ }^{2}$ Orientador do trabalho e professor de Departamento de Ciências Humanas, da Faculdade de Arquitetura, Artes e Comunicação, Campus da UNESP - Bauru/SP.
} 
Keywords: Media. Exclusivity. Monopoly. Oligopoly. Regulation of the media.

\section{Introdução}

$\mathrm{O}$ projeto de pesquisa em iniciação científica $^{3}$, cujos resultados se apresentam neste trabalho, visou investigar a regulação ${ }^{4}$ jurídica constitucional da propriedade dos meios de comunicação e para tanto revisitou ao processo constituinte de 1987/88 no intuito de verificar e interpretar, em uma perspectiva histórica e também dogmática, a regulação jurídica almejada durante o processo constituinte para a propriedade dos meios de comunicação e para a divulgação de informações.

Partiu o projeto de alguns pressupostos: que a atual constituição brasileira, de 05 de outubro de 1988, tem caráter substancial, programática, dirigente, tendo em vista que ela estipula inúmeras finalidades, objetivos e valores que o Estado e a sociedade brasileira devem concretizar ou pelo menos almejar; que a regulação da propriedade dos meios está inserida dentro de um conjunto de direitos que recentemente passou a ser denominado direito à comunicação ${ }^{5}$, recebendo esse conjunto de direitos nítido caráter substancial; que a constituição de 88 prevê que este mercado deve ter caráter plural e diverso, tanto no que diz respeito à propriedade dos meios quanto à divulgação das informações por parte das empresas de comunicação social; que essa temática é recorrentemente tratada nos debates jurídicos e políticos nacionais, haja vista, discussões a respeito do monopólio da Rede Globo de Televisão na transmissão do Campeonato Brasileiro de Futebol da Série A.

\footnotetext{
${ }^{3}$ O projeto de pesquisa de iniciação científica foi financiado pela FAPESP processo 2011/06542-4.

${ }^{4} \mathrm{O}$ termo regulação está sendo usado no presente trabalho no sentido de regulação normativa que compreende, segundo Aguillar (2006), a regulamentação legal e as atividades acessórias de fiscalização e imposição de sanções para as condutas ilícitas. São, portanto, medidas estatais, tanto legislativas como administrativas, que visam controlar e ou influenciar os comportamentos "dos agentes econômicos, tendo em vista orientá-los em direções desejáveis e evitar efeitos lesivos aos interesses socialmente legítimos (CARVALHO, 2002). Regular, em outras palavras, seria definir direitos e deveres, delimitar o exercício de direitos, clarificar as suas condições de uso, defender a sociedade e o indivíduo contra eventuais maus usos dos direitos (GONÇALVES, 2003, p. 7).

${ }^{5}$ A pesquisa considera que o direito à comunicação é composto por um conjunto de direitos isolados, relacionados à regulação jurídica da comunicação, que reunidos se transformam naquele. Dentro desses direitos que compreendem o direito fundamental à comunicação podem ser relacionados: o direito à liberdade de expressão, a regulamentação quanto à pluralidade e diversidade nos meios de comunicação, o direito de antena, a regulamentação dos meios de comunicação social e comunitária, a propriedade dos meios, a liberdade de imprensa, o direito de informação, o direito à informação, a liberdade de opinião, os direitos relacionados à propriedade imaterial, dentre outros, conforme Brant e Kameoka (2005).
} 
Considerou nesse sentido a pesquisa que um dos valores substantivos almejados no processo constituinte foi, sem dúvida, à proteção e a concretização do direito fundamental ${ }^{6}$ à comunicação, prevendo-se como regra um mercado plural em relação à propriedade dos meios e à divulgação de das informações por parte das empresas de comunicação social.

Este pressuposto está fundamento em alguns dispositivos constitucionais, como, por exemplo, no preâmbulo da Constituição da República Federativa do Brasil que estabelece que o Estado brasileiro deve assegurar o exercício dos direitos sociais e individuais, a liberdade, a segurança, o bem-estar, o desenvolvimento, a igualdade e a justiça como valores supremos de uma sociedade fraterna, pluralista e sem preconceitos.

Por esse prelúdio já dá para extrair que, em termos constitucionais, a ideia vigente é da pluralidade e da diversidade nas questões políticas e sociais.

Também prevê o artigo $5^{\circ}$, ao tratar dos direitos e garantias fundamentais, que todos que convivem em nossa sociedade, sejam eles brasileiros ou estrangeiros, são iguais perante a lei, não sendo admitidas distinções de qualquer natureza, garantindo-se a inviolabilidade do direito à vida, à liberdade, à igualdade, à segurança e à propriedade, especificando, em relação ao direito à liberdade, que é inviolável a liberdade de consciência e de crença, que é livre a expressão da atividade intelectual, artística, científica e de comunicação, independentemente de censura ou licença, que é livre a manifestação do pensamento, além de inúmeros outros direitos e garantias que fundamental o direito à comunicação.

Ainda no artigo 220 a constituição federal, ao tratar especificamente da comunicação social, estabelece regras relativas à pluralidade e à diversidade nos meios de comunicação e na veiculação de informações, dispondo que a manifestação do pensamento, a criação, a expressão e a informação, sob qualquer forma, processo ou veículo não sofrerão qualquer restrição, observado somente os limites estabelecidos na própria constituição.

Menciona ainda, limitando a discricionariedade do legislador, que nenhuma lei infraconstitucional poderá conter qualquer dispositivo que possa constituir embaraço à plena

\footnotetext{
${ }^{6}$ A teoria dos direitos fundamentais enfoca o mesmo tema com expressões diversas, tais como, direitos fundamentais, direitos do homem, direitos humanos, direitos subjetivos públicos, liberdades públicas, direitos individuais, liberdades fundamentais, além de outras tantas. A expressão "direitos fundamentais" é tida como a mais adequada, pela teoria jurídica brasileira, pois foi a adotada no texto da constituição federal. A título de observação Bonavides (2000) menciona que a expressão "direitos humanos" é mais utilizada entre os autores anglo-americanos e latinos, enquanto a expressão "direitos fundamentais" é mais utilizada pelos teóricos alemães. Já para Schäfer (2001), direitos fundamentais são aqueles reconhecidos e previstos nas constituições, enquanto os direitos humanos são aqueles previstos nos documentos de direito internacional, como os casos dos tratados internacionais sobre direitos humanos.
} 
liberdade de informação jornalística em qualquer veículo de comunicação social; que é vedada toda e qualquer censura de natureza política, ideológica e artística; que os meios de comunicação social não podem, direta ou indiretamente, ser objeto de monopólio ou oligopólio e que a publicação de veículo impresso de comunicação independe de licença de autoridade.

Deste modo, verifica-se que a ideia matriz da constituição é de não admitir, tolerar qualquer tipo de monopolização ou oligopolização, seja na propriedade dos meios, ou até mesmo na transmissão das informações, sendo a diversidade de pensamento, de culturas, de opiniões, de informações um norte que deve ser seguido pelo nosso Estado e pela nossa sociedade.

Esses são alguns exemplos extraídos do texto constitucional, base jurídica do Estado brasileiro, referentes ao tema pluralidade e diversidade nos meios de comunicação e na veiculação de informação, que não só deve ser almejado, mas também concretizado pelo Estado e pela sociedade brasileira.

Por hipótese, a pesquisa partiu do pressuposto que a intenção constituinte, no plano jurídico normativo, foi a de impor severas restrições à propriedade dos meios de comunicação, proibindo-se, de forma clara, no artigo $220, \S 5^{\circ}$, a formação de monopólios e/ou oligopólios no setor, para, em consequência, propiciar um mercado plural e diversificado na veiculação de informações.

No entanto, compreende-se que, no plano da realidade, muitas empresas de comunicação atuam de forma ilegal, ora em forma de oligopólio ou até mesmo monopolizando determinados setores da economia, ora, controlando as informações veiculadas por essas empresas, como pode ser verificado na recente questão acerca do monopólio dos direitos de transmissão dos jogos do Campeonato Brasileiro de Futebol da Série A, por parte da Rede Globo de Televisão, tema que será utilizado para justificar a ilegalidade apontada para o setor.

Para cumprir os objetivos a pesquisa analisa as propostas e os debates legislativos durante o processo constituinte de 87/88, relativos à regulação do direito à comunicação, especificamente, em relação à proibição do monopólio e do oligopólio. A pesquisa é realizada nos Diários do Congresso Nacional (DCN), organizados em CD-ROM, em 2008, pela Secretaria Especial de Editoração e Publicação do Congresso Nacional, que contém na íntegra os debates constituintes. 
Inicialmente pensou-se, tendo em vista a imensidão ${ }^{7}$ das informações contidas nos DCN, a realização da pesquisa através de buscas por palavras-chave relacionadas à temática da investigação.

No entanto, no início das investigações percebeu-se que não houve sistematização nas atividades da ANC, por essa razão optou-se em analisar os pareceres dos relatores da Subcomissão da Ciência e Tecnologia e da Comunicação, da Comissão Temática da Família, Educação, Cultura e Esportes, Ciência e Tecnologia e da Comunicação, da Comissão de Sistematização e do Plenário da Assembleia Nacional Constituinte.

Essa opção se justifica, tendo por base trabalho de Souza (2003, p. 43), que analisou o processo decisório durante a constituinte, para quem os relatores, no âmbito congressual, exercem

Um papel importante nos processos decisórios na medida em que influem sobremaneira na elaboração dos anteprojetos encaminhados à votação. Como centralizadores de todas as informações disponíveis no âmbito de sua atuação formal, os relatores dispõem de um amplo raio de intervenção no que se refere ao conteúdo mesmo das proposições contidas em seus pareceres.

Levou-se ainda em consideração o roteiro de elaboração constitucional que "devia começar pelas 24 subcomissões temáticas, que entregariam seus anteprojetos a 8 comissões temáticas e estas, seus anteprojetos à Comissão de Sistematização, que por sua vez entregaria ao Plenário da ANC o Projeto de Constituição" (PILATTI, 2008, p. 57).

Ademais, constatou-se que a divisão inicial dos trabalhos constituintes reflete, com algumas poucas alterações, o resultado final do processo constituinte. Como exemplo, a comunicação social foi alocada na oitava comissão. Na redação final da constituição essa temática ficou alocada no Título VIII (Da Ordem Social).

Como exemplo de simetria entre os trabalhos das comissões e o texto final, fato que justifica essa opção de análise dos Diários, observe-se que vários itens propostos no primeiro parecer da subcomissão estão presentes no texto constitucional, com algumas poucas alterações. Como exemplos: a reserva de mercado para brasileiros natos na propriedade das empresas de comunicação; a proposta de criação de um conselho, inicialmente denominado Conselho Nacional

\footnotetext{
${ }^{7}$ Para se ter uma ideia da dimensão dos dados a Assembleia Nacional Constituinte foi instalada em 02 de fevereiro de 1987 e terminou em 05 de outubro de 1988, com a promulgação da nova constituição. Nesse período (um ano, oito meses e três dias), foram realizadas 341 sessões plenárias. Para cada sessão há um diário com o registro de todas as falas e proposições.
} 
de Comunicação; a previsão de princípios para a radiodifusão, tais como a finalidade educativa, a regionalização, dentre outras, conforme proposta da relatora da subcomissão (Secretaria Especial de Editoração e Publicações - SEEP, 2008a), além da proposta de colocar-se um dispositivo expresso no texto constitucional proibindo-se o monopólio e o oligopólio dos meios.

Concomitante a pesquisa nos DCN, analisou-se também a decisão proferida pelo Conselho Administrativo de Defesa Econômica (CADE), órgão responsável pela fiscalização de mercados, no processo administrativo proposto pela Secretaria do Direito Econômico em relação à Rede Globo de Televisão, e que trata do monopólio das transmissões do Campeonato Brasileiro de Futebol da série A. Abaixo seguem os resultados da pesquisa.

\section{Resultados da pesquisa: análise do relatório da Subcomissão de Ciência e Tecnologia e da Comunicação}

No parecer da relatora da subcomissão, Deputada Cristina Tavares, especial destaque foi dado para as Políticas Democráticas de Comunicação.

Verifica-se no parecer que a ideia inicial da ANC era tratar a informação como "um recurso social vital" (SEEP, 2008a, p. 152), por isso "quanto mais amplos, diversificados, plurais forem os meios e as tecnologias, maior será a quantidade, logo o valor, da informação socialmente produzida e recebida." (SEEP, 2008a, p. 153).

Ainda para a relatora, a comunicação social exerce fundamental papel para o acesso e difusão da informação, pois "é essencial na construção das formas pelas quais a sociedade, como um todo, pensa a respeito de si mesma, define seus projetos estratégicos, estabelece seus padrões morais, éticos, políticos, etc.” (SEEP, 2008a, p. 153).

Quanto à radiodifusão assevera que "o rádio e, depois, a televisão foram e continuam sendo fundamentais na construção do imaginário fáustico do moderno homem ocidental. No Brasil, estes dois meios foram de grande importância como veículos de integração cultural e política da Nação" (SEEP, 2008a, p. 153).

Segundo ainda a relatora

Do exame das muitas idéias trazidas a esta Sub-comissão por diferentes entidades e personalidades ouvidas, surge a convicção de estar madura em nosso País, a possibilidade de introduzirmos constitucionalmente novas regras para assegurar o funcionamento democrático dos meios de comunicação. Assegurada a liberdade de iniciativa 
empresarial, considerou-se, também, importante subordinar essa liberdade aos objetivos sociais. (SEEP, 2008a, p. 153).

Especificamente, quanto à propriedade dos meios a relatora entende que

em todos os países industriais avançados, as telecomunicações desenvolveram-se sob o regime de monopólio. Tal é necessário para assegurar a compatibilidade entre tecnologias industriais diferentes e, também, possibilitar o financiamento de serviços deficitários mas socialmente necessários pelos mais rentáveis. No Brasil de hoje, existem grandes e consolidados sistemas de comunicação social, privados (em sua maioria) ou estatais, com os quais o projeto constitucional ora apresentado não pretende interferir, mantendo-se, inclusive, regras já consagradas e aceitas como, por exemplo, a exigência de serem as empresas e veículos dirigidos por brasileiros natos. Vislumbra-se um novo cenário, dentro do qual grandes organizações empresariais conviverão com produtores mantidos por entidades culturais ou comunitárias, num ambiente verdadeiramente democrático. (SEEP, 2008a, p. 153).

Diz ainda a relatora que "o projeto constitucional sugere que aproveitemos este momento de mudanças sociopolíticas coincidindo com transformações tecnológicas para multiplicarmos os meios pelos quais a sociedade poderá falar" (SEEP, 2008a, p. 153).

Conclui que as ideias que convergiram para a subcomissão apontavam para:

1 - obter-se o maior controle da sociedade sobre os conteúdos dos meios de comunicação que colocam em suas casas; 2 - agregar um caráter social ao uso que se faz dos meios de comunicação, fazendo servir à população e ao seu real interesse (SEEP, 2008a, p. 155).

Verifica-se no parecer da relatora que a força motriz na constituinte para a comunicação social era o reconhecimento da sua importância para as práticas democráticas e para a consolidação da democracia, reconhece-se a liberdade de imprensa e de opinião como direitos fundamentais do cidadão.

No entanto, percebe-se a preocupação com a produção e a difusão da informação, reconhecidas como recursos vitais da sociedade, bem como com a concentração da propriedade dos meios, almejando a ANC a pluralidade e a diversidade de meios para a difusão de informações. Nessa linha, sugere a inovação constitucional para introduzir no sistema jurídico pátrio mecanismos para garantir o funcionamento democrático dos meios de comunicação, subordinando a sua atuação aos objetivos sociais e não mais somente aos empresariais, proibindo-se, deste modo, mercados monopolizados ou oligopolizados. 


\section{Análise do relatório da Comissão Temática da família, educação, cultura e esportes, ciência e tecnologia e comunicação.}

Na comissão temática o relator Artur da Távola apresenta ideia inovadora, no debate constituinte, acerca da complementaridade tripartite da concessão dos serviços de telecomunicações, em privado, estatal e público. E explica essa complementaridade seria a melhor maneira para que o Brasil, que tem a maior parte de suas concessões nas mãos de empresa privadas, adotasse também o sistema público. Essa divisão enfrentaria diretamente a questão do monopólio e do oligopólio dos meios e seria feita da seguinte forma:

O sistema privado que possui dinâmica própria, que atua, com muita eficácia, no setor de entretenimento, que é um acicate ao desenvolvimento econômico, que é campo adequado para a publicidade, para o desenvolvimento da economia que advém da aceleração do consumo, que atende à população nas suas necessidades de lazer, que consulta, constantemente, o mercado, para elaboração dos seus produtos (...). Do outro lado, o Estado, que deve continuar a merecer um tipo de concessão, porque cabe ao Estado uma série de tarefas que não podem ser realizadas no campo da comunicação, pela iniciativa privada, até porque não são rentáveis, e que são, também, fundamentais: o auxílio a programas de ensino, a inserção nos currículos escolares, a complementação no tocante à matéria de natureza educativa e cultural à organização de cursos de intercâmbio universitário (...) e, juntamente com esses dois sistemas, a oferta de um sistema de comunicação. Trata-se de um sistema organizado por instituições da sociedade e que funciona independente do Estado e do capital. Se esta Nação tiver, oriunda dos meios de comunicação, essas três propostas de comunicação convivendo no campo social, seguramente ela terá encontrado o caminho da democratização.

Segundo o relator o direcionamento estatal para as atividades privadas, que vigorou no período autoritário, deve ser superado, pois

uma democracia não possui apenas o capital e o Estado como instituições sociais. O capital é importante, é presença indispensável, o Estado é o organismo que representa as aspirações coletivas. Mas, Estado e capital não são as duas únicas instâncias sociais de um país. (SEEP, 2008b, p. 178).

Por essa razão propõe um sistema tripartite de concessões. Alega que este é o sistema usado nos países desenvolvidos e justifica a proposta da seguinte maneira:

concessão ao sistema privado que possui dinâmica própria, que atua, com muita eficácia, no setor de entretenimento [...]. Eu acho que a iniciativa privada tem um papel fundamental nas comunicações. Não tem direito ao papel monopolista, como ocorre, hoje, no Brasil. Cabe-lhes ter o seu espaço preservado, até porque o Brasil realiza uma televisão de qualidade. Do outro lado, o Estado, que deve continuar a merecer um tipo de 
concessão, porque cabe ao Estado uma série de tarefas que não podem ser realizadas no campo da comunicação, pela iniciativa privada, até porque não são rentáveis, e que são, também, fundamentais: o auxílio a programas de ensino, a inserção nos currículos escolares, a complementação no tocante à matéria de natureza educativa e cultural à organização de cursos de intercâmbio universitário, enfim, um sem número de atividades que cabem ao Estado na área da comunicação, e, juntamente com esses dois sistemas, a oferta de um sistema de comunicação. Trata-se de um sistema organizado por instituições da sociedade e que funciona independente do Estado e do capital. Se esta Nação tiver, oriunda dos meios de comunicação, essas três propostas de comunicação convivendo no campo social, seguramente ela terá encontrado o caminho da democratização. (SEEP, 2008b, p. 178).

Verificou-se nas atas da comissão que as votações do parecer do relator foram extremamente tumultuadas, sendo o resultado final da comissão a não aprovação de nenhum anteprojeto, conforme SEEP (2008b, pp. 279/280).

Muito embora a comissão nada tenha decidido, observe-se que a semente lançada sobre a concessão tripartite surte efeitos tanto é que o texto final contempla essa questão. Compreende-se que se de fato o sistema tripartite fosse colocado em prática seria um grande passo para se assegurar a pluralidade dos meios e do fluxo de informações.

\section{Análise do relatório da Comissão de Sistematização}

A Comissão de Sistematização, devido à escolha do modelo decisório fragmentado da ANC, foi pensada para atribuir-se maior coesão e sistematicidade para o processo constituinte, bem como para excluir eventuais contradições do conjunto das proposições apresentadas nas fases anteriores. Assim, ficaria a Comissão de Sistematização encarregada de elaborar um anteprojeto da constituição.

No entanto, nesta comissão, como nas fases anteriores muitos foram os problemas e poucas as deliberações e segundo Pilatti (2008, p. 175) "transformara-se em muro de lamentações dos outsiders, abandonada desde logo pelo próprio relator".

Para ilustrar a falta de deliberações nesta fase, verificou-se nos Diários, que o relator Bernardo Cabral, elaborou dois relatórios substitutivos, que ficaram conhecidos como Cabral 1 e 2, mas das trinta reuniões que ocorreram para as votações do $2^{\circ}$ substitutivo, o relator compareceu em apenas 17 delas, e nas oito em que havia projetos para votação, em nenhuma houve quórum suficiente, sendo que em seis dessas o relator não estava presente. 
Para exemplificar o descontentamento dos constituintes com o rumo das discussões e votações, especialmente, em relação à temática da comunicação social, verificou-se a seguinte fala proferida pelo constituinte Carlos Alberto Caó ${ }^{8}$

Sr. Presidente, de forma muito breve e objetiva, gostaríamos de nos incorporar às manifestações de inconformismo aqui feitas, em face da não discussão de capítulos de extrema importância para a prática democrática em nosso País. Realmente, algo de estranho, muito estranho, ronda essa questão das Comunicações. [...] pela terceira vez, nós somos, por algum fato imprevisto, por alguma coisa nebulosa, impedidos de discutir o problema da comunicação e, sobretudo, do monopólio das telecomunicações, que envolve questões de segurança e soberania nacional. (SEEP, 2008b, p. 380).

No entanto, apesar da falta de deliberação e o descontentamento com os rumos que estavam sendo dados para a regulação constitucional da comunicação social, verifica-se que no anteprojeto foram mantidas diversas regras propostas nas fases anteriores, em especial, a regra proibitiva do monopólio e oligopólio sobre a propriedade dos meios.

\section{Análise do relatório do Plenário da Assembleia Nacional Constituinte}

O início das votações no Plenário foi caracterizado por forte tensão entre os constituintes. Essa tensão fez com que as primeiras votações continuassem no impasse, mas os constituintes logo perceberam que para conseguir a maioria suficiente para aprovação do texto era necessário estabelecer acordos. Com isso as votações começaram a fluir.

De acordo com Pilatti (2008, p. 272)

Ao contrário do que acontecera em todas as fases anteriores com os temas relativos aos Capítulos IV (Ciência e Tecnologia) e V (Comunicação) do Título VIII, a votação em Plenário das respectivas emendas substitutivas apresentadas pelo Centrão foi marcada pelo entendimento [...]. A rigor, sobre esses temas o entendimento tinha se iniciado com a votação do monopólio das telecomunicações, no Título II.

Graças a esse acordo, pela primeira vez uma constituição brasileira teria um capítulo sobre comunicação social. Esse capítulo agregaria várias questões discutidas e apresentadas desde a subcomissão de Ciência e Tecnologia e da Comunicação, mas ao mesmo tempo em diversos pontos o texto aprovado não se deu nos termos desejados nas etapas anteriores.

\footnotetext{
${ }^{8}$ O deputado Carlos Alberto Caó foi o constituinte que, em primeira mão, apresentou proposta proibitiva do monopólio / oligopólio na propriedade dos meios.
} 
Foi exatamente nessa fase do processo constituinte que foi encontrada pela pesquisa a única menção expressa à exclusividade nas transmissões de eventos esportivos, objeto de estudo desse trabalho. O constituinte Inocêncio de Oliveira apresentou uma proposta que vedaria em todo o território nacional, às emissoras de rádio e de televisão, a exclusividade nas transmissões de eventos esportivos de qualquer natureza, nos seguintes termos

É de interesse do público telespectador esportivo acompanhar pela televisão a realização de partidas de futebol em que o clube que apresenta sua região ou aquele de que é torcedor esteja disputando o jogo daquele dia. No entanto, já está se tornando hábito verse esse público privado de acompanhar esses eventos esportivos, vez que, quer no futebol, quer no basquetebol, vôlei e outros esportes, as emissoras de televisão se aperfeiçoaram no sistema de competição pela exclusividade na transmissão do acontecimento esportivo, não pelo de importante que haverá em si, mas sobretudo visando a impossibilidade de que suas congêneres lhes tirem a liderança de audiência naquele horário. Fica, então, o telespectador entregue à caprichosa programação das emissoras que detêm a exclusividade das transmissões contratadas de antemão, sem alternativa de escolher outro canal que pudesse estar transmitindo esses jogos. (SEEP, 2008b, p. 203).

Essas observações ilustram que enquanto o assunto da regulação da comunicação estava nos pequenos foros da subcomissão e da comissão temática a oposição, amparada por entidades representativas da sociedade, teve forças para levar a discussão adiante, mas no plenário, contudo, os interesses dos majoritários parlamentares concessionários ou aliados de concessionários de emissoras de rádio e TV fizeram impor sua vontade. (JAMBEIRO, 2009).

A única exceção à observação apontada é exatamente a vedação constitucional do monopólio e oligopólio dos meios que restou regulada pelo artigo 220 , $5^{\circ}$, nos seguintes termos: “Os meios de comunicação social não podem, direta ou indiretamente, ser objeto de monopólio e oligopólio."

\section{Análise do processo administrativo nº $08012.006504 / 1997$}

Para justificar a hipótese que, no plano da realidade, muitas empresas de comunicação atuam de forma ilegal, ora em forma de oligopólio ou até mesmo monopolizando determinados setores da economia, ora, controlando as informações veiculadas por essas, a pesquisa analisou o caso específico da transmissão do Campeonato Brasileiro de Futebol da Série A, pela Rede Globo de Televisão. 
A venda desses direitos de transmissão à emissora carioca é feita, através de contrato, pela Associação Brasileira de Futebol - Clube dos Treze, e apresenta cláusulas que podem ser consideradas embaraçosas à livre concorrência.

A Secretaria do Direito Econômico (SDE) ajuizou uma representação junto ao Conselho Administrativo de Defesa Econômica (CADE) em 5 de fevereiro de 2008. A representação envolvia as seguintes partes: Associação Brasileira dos Clubes de Futebol - Clube dos Onze; a Associação Brasileira de Futebol - Clube dos Treze; Confederação Brasileira de Futebol (CBF); Globosat; Rede Bandeirantes de Televisão; Rede Globo de Televisão e TVA.

Por meio dessa representação, a SDE argumentou que a venda e a transmissão do Campeonato Brasileiro de Futebol da Série A apresentava conduta anticoncorrencional e deveria ser modificada pelos seguintes fatos: em 1997 a Rede Globo e a Rede Bandeirantes firmaram contrato com o Clube dos Treze, com o aval da CBF, para transmitir, com exclusividade, os jogos do Campeonato Brasileiro de Futebol da Série A, nos anos 97, 98 e 99. E, no mesmo ano, o clube dos 11 firmou o mesmo contrato com a TVA.

A SDE aponta que tanto a formação do Grupo dos Treze, como a formação do Clube dos Onze apresenta irregularidades, dentre elas o fato de que a formação de qualquer bloco entre pessoas jurídicas de direito privado adotando conduta comercial, visado tirar proveito econômico, caracteriza-se como cartel. O Clube dos Treze e dos Onze constituem blocos de propósitos nitidamente comercial, ou seja, vender os direitos de transmissão de seus jogos, em conjunto, com vistas a auferir melhor preço. Portanto, essa conduta incorre em infração às normas do direito de concorrência. Assim, segundo os argumentos da SDE os direitos dos clubes deveriam ser exercidos singularmente.

Ainda, segundo a SDE, as redes de televisão também estão agindo de forma irregular, pois a Rede Globo teve que se associar a Globosat e a Rede Bandeirantes para cobrir a proposta de uma só empresa: no caso, o SBT. Além disso, alega que

a exclusividade imposta nas transmissões constitui forte elemento caracterizador do abuso do poder econômico, acarretando danos à concorrência, uma vez que outras emissoras não podem negociar as transmissões diretamente com os clubes, bem como o mercado de telespectadores, que ficam restritos aos jogos impostos pelo pool das emissoras, que estranhamente transmitem os mesmo jogos, não levando em consideração as peculiaridades regionais. (BRASIL, 2010). 
A SDE apresenta diversas vantagens que justificariam o fim da exclusividade, dentre elas a maior oferta que beneficiaria diretamente os consumidores, proporcionaria maior envolvimento de jornalistas, repórteres, narradores, operadores de câmera. Acarretaria também uma melhor qualidade de transmissão, uma vez que com a exclusividade, não há disputa, não há concorrência entre as emissoras por uma transmissão de melhor qualidade.

A exclusividade ainda gera uma dificuldade quando o jogo acontece em horário já ocupado pela grade da emissora. Em muitos casos, o jogo não é transmitido.

Outra irregularidade apontada pela SDE é sobre a cláusula de preferência existente nos contratos firmados entre a Rede Globo e o Clube dos Treze garantindo-se à emissora carioca a primazia na hora de renovar a adquisição do pacote de transmissão do Campeonato Brasileiro de Futebol da Série A. O primeiro contrato de cessão dos direitos de transmissão firmado entre o Clube dos Treze e as Redes de Televisão Globo e Bandeirantes foi assinado no dia 7 de abril de 1997, tendo como abrangência as temporadas de 1997, 1998 e 1999. Neste contrato, foi convencionado que Globo e Bandeirantes teriam direito de preferência na compra dos direitos de transmissão das temporadas futuras. Essa cláusula esteve presente em todos até a propositura da representação em análise.

Portanto, segundo a SDE o caso envolve o comportamento cartelizado dos clubes, das emissoras de TV, além da questão da preferência e da exclusividade.

Após analisar as proposições da SDE, o CADE instaura processo administrativo para averiguação dos fatos alegados. Depois de vários trâmites processuais, o relator César Costa Alves de Mattos profere voto manifestando-se sobre a possível conduta anticoncorrencial na venda e transmissão dos jogos do Campeonato Brasileiro da Série A.

Sobre a cláusula de exclusividade, o relator sustenta que ela pode ser benéfica, pois geraria eficiências econômicas. A partir disso, conclui-se que é lícita a utilização de cláusula de exclusividade nos contratos examinados, e, portanto, não há necessidade de modificar esse aspecto dos contratos.

O relator também aponta para o fato de os esportes serem de grande interesse publicitário por atraírem uma audiência homogênea, sendo o seu público majoritariamente jovem e masculino. Quanto à importância do Campeonato Brasileiro frisa que esta é a competição qua agrupa os melhores e mais tradicionais times do país, justamente os que contam com as maiores torcidas, além de ter uma duração maior do que qualquer outro campeonato, nacional ou internacional. 
No entanto, graças a tamanha importância do Campeonato Brasileiro da Séria A, a exclusão de outras emissoras dos direitos de transmissão gera um impacto negativo na grade televisiva das concorrentes. Isto indicaria que exclusividade apresenta um potencial anticompetitivo.

Ainda segundo o relator, como nesse mercado as restrições à exclusividade são vistas com ressalvas, o sublicenciamento seria uma alternativa para aumentar a oferta de jogos e agradar o consumidor. Nesse caso, para que a conduta seja pró-concorrência, o sublicenciamento deve estar amparado por regras que confiram maior flexibilidade à emissora sublicenciada, de tal modo que tenha condições de escolher qual, dentre os jogos destinados à transmissão pela TV aberta, transmitirá.

Quanto à avaliação do Clube dos Treze como cartel, o relator aponta para o fato de que a produção do evento futebol passa necessariamente pela co-produção de dois times. Além disso, o Clube dos Treze apresenta potencial de agregar valor à competição como um todo, o que caracteriza o acordo entre os clubes como pró-concorrencial.

Antes da decisão do plenário do CADE, a Rede Globo e o Clube dos Treze firmaram um Termo de Compromisso de Cessação de Prática. Com a assinatura do TCC, o CADE, deliberou, pelo arquivamento do processo, enquanto os termos de compromisso estiverem sendo cumpridos.

O TCC assinado pelas partes teve por objetivo preservar e proteger as condições concorrenciais para comercialização dos direitos de captação, fixação, exibição e transmissão dos jogos do Campeonato Brasileiro de Futebol da Série A, nas seguintes modalidade: televisão aberta, televisão fechada, pay-per-view, internet e telefonia móvel.

Selado o compromisso o Clube dos Treze assume as seguintes obrigações: abster-se de utilizar a "Cláusula de preferência", nos novos contratos de comercialização de transmissão dos jogos nas cinco modalidades; realizar a venda dos direitos de transmissão dos jogos CBFA de modo separado para cada uma das cinco modalidades, podendo facultar aos interessados realizar propostas isoladas, combinadas ou conjuntas pelas modalidades; definir critérios claros e objetivos na realização das concorrências; permitir ao vencedor do certame, na mídia televisão aberta, sublicenciar os direitos adquiridos a terceiros. Em havendo sublicenciamento, o sublicenciado poderá escolher livremente, dentre os jogos disponíveis para televisão aberta, aquele que transmitirá a cada rodada.

Além disso, estabelece-se a obrigação do Clube dos Treze apresentar ao CADE cópia autenticada dos contratos firmados, no prazo de 30 dias a contar da assinatura do mesmo, bem como 
relatório explicando como ocorreu o processo da venda e os motivos que levaram à escolha dos vencedores

O Compromisso estabelecido vigorará pelo prazo de cinco anos a contar da publicação do TCC no Diário Oficial da União e o processo administrativo ficará em suspenso durante o Compromisso. Caso ele seja cumprido o processo será arquivado. Caso seja constatado o descumprimento será retomado.

Já a Rede Globo assume a obrigação de renunciar aos direitos de preferência da transmissão dos jogos de 2009, 2010 e 2011, em Tv de assinatura, Tv aberta, pay-per-view e telefonia móvel. Mas essa renúncia não interfere na liberdade da Globo de comprar, os direitos das mídias de forma isolada, ou até mesmo de todas as mídias, das temporadas de 2012 e seguintes anos. Tais renúncias deverão ser formalizadas por meio de alterações contratuais a serem celebradas entre a Globo e o Clube dos Treze. Se por qualquer razão não for possível fazer referidas alterações, a Globo deverá apresentar ao CADE um termo de renúncia

O Compromisso assinado pela Rede Globo vigorará pelo prazo compreendido entre a publicação do TCC no Diário Oficial da União e a publicação da decisão do CADE atestando o cumprimento das obrigações assumidas. O processo administrativo ficará suspenso durante o Compromisso. Caso ele seja cumprido o processo será arquivado. Caso seja constatado o descumprimento será retomado.

Analisando o processo pode-se notar que pouca coisa foi alterada na forma como ocorre a venda e a transmissão dos jogos do Campeonato Brasileiro da Série A. A única mudança real que as partes terão que fazer a partir dos termos de compromisso é excluir a cláusula de preferência, que garantia a Rede Globo grande vantagem sobre as demais concorrentes.

Quanto à exclusividade, apesar da SDE ter apresentado diversos benefícios com o fim dessa cláusula, principalmente para os consumidores, o CADE sustenta que ela pode ser benéfica, e, portanto continua sendo legal. Essa resolução não ajuda a diminuição do monopólio por parte da emissora vencedora dos certames, tanto por parte da Rede Globo, como pelas concorrentes. Um exemplo disso foi a transmissão dos jogos Panamericanos com exclusividade pela Rede Record.

A transmissão de eventos esportivos já se mostrou um dos principais atrativos de audiência e publicidade que existe na mídia brasileira, e mesmo com essa grande importância, a transmissão do Campeonato Brasileiro da Série A é feita de forma a beneficiar o lucro dos times e das emissoras, 
em detrimento do consumidor, que não conta com variedade de jogos e nem melhora nas transmissões, devido à falta de concorrência.

\section{Conclusão}

Conforme acima apresentado a ANC, desde o início dos trabalhos, almejou proibir qualquer tipo de monopólio ou oligopólio nos meios de comunicação social, seja ele estatal ou privado, para garantir a democratização e a pluralidade da informação.

Essa proibição almejada restou regulamentada no artigo 220 , parágrafo $5^{\circ}$ da atual constituição que prevê que os meios de comunicação social não podem, direta ou indiretamente, ser objeto de monopólio ou oligopólio.

Além dessa probição expressa, outra medida importante para a democratização dos meios foi a implementação do sistema tripartite de concessõe fato que demonstra profunda preocupação da ANC com a diversidade e pluralidade na propriedade dos meios de comunicação.

No entanto, apesar de todas essas preocupações da ANC acerca do tema monopólio/oligopólio, pluralidade/diversidade na propriedade dos meios, verifica-se no plano da realidade que esses dispositivos constitucionais não são respeitados, conforme ficou constatado no caso da transmissão dos jogos de futebol do campeonato brasileiro da séria A.

Note-se que no processo apreciado pelo CADE vários aspectos causadores de embaraço a livre concorrência foram apontados, mas a única mudança real determinada no processo foi a exclusão da cláusula de preferência, que garantia a Rede Globo enorme vantagem sobre as demais concorrentes, não havendo qualquer alteração quanto à exclusividade nas transmissões, fato que restringe demasiadamente o acesso a informação, direito fundamental do cidadão.

\section{Referências}

AGUILLAR, F. H. Direito econômico. São Paulo: Atlas, 2006.

BONAVIDES, P. Curso de direito constitucional. 10. ed. São Paulo: Malheiros, 2000.

BRANT, J.; KAMEOKA, M. (Coord.). Direito à comunicação no Brasil. Intervozes - Coletivo Brasil de Comunicação Social: jun. 2005. Disponível em: <www.scribd.com/doc/5619429/Direitoa-comunicacao-no-Brasil-Intervozes $>$. Acesso em: vários acessos.

BRASIL. Processo Administrativo no 08012006504/1997-11, 2010. Disponível em: < http://www.cade.gov.br/>. Acesso em: 6 out. 2011.

CARVALHO, V. M. de. Regulação de serviços públicos e intervenção estatal na economia. In: FARIA, J. E. Regulação, direito e democracia. São Paulo: Ed. Fundação Perseu Abramo, 2002. 
GONCALVES, M. E. Direito da informação: novos direitos e formas de regulação na sociedade da informação. Coimbra: Ed. Almedina, 2003.

JAMBEIRO, O. A comunicação na Constituição de 1988, in: GOULART, J. O. As múltiplas faces da Constituição Cidadã. São Paulo: Cultura Acadêmica Editora, 2009.

PILATTI, A. A Constituinte de 1987-1988: progressistas, conservadores, ordem econômica e regras do jogo. Rio de Janeiro: Ed. Lúmen Júris, 2008.

SCHÄFER, J. G. Direitos fundamentais, proteção e restrições. Porto Alegre: Livraria do Advogado Editora, 2001.

SECRETARIA ESPECIAL DE EDITORAÇÃO E PUBLICAÇÕES. Secretaria de Anais.

Assembleia Nacional Constituinte - 20 anos: Atas da Subcomissão de Ciência e Tecnologia e da Comunicação. Brasília, 2008a.

. Secretaria de Anais. Assembleia Nacional Constituinte - 20 anos: Atas da Comissão da Família, da Educação, Cultura e Esportes, da Ciência e Tecnologia e da Comunicação. Brasília, 2008b.

SOUZA, M. T. O processo decisório na constituição de 1988: práticas institucionais. Lua Nova. n.58, p. 37-60, São Paulo, 2003. 